\title{
Social Geography of \\ Developmental Health \\ in the Early Years
}

Cyreteresnan
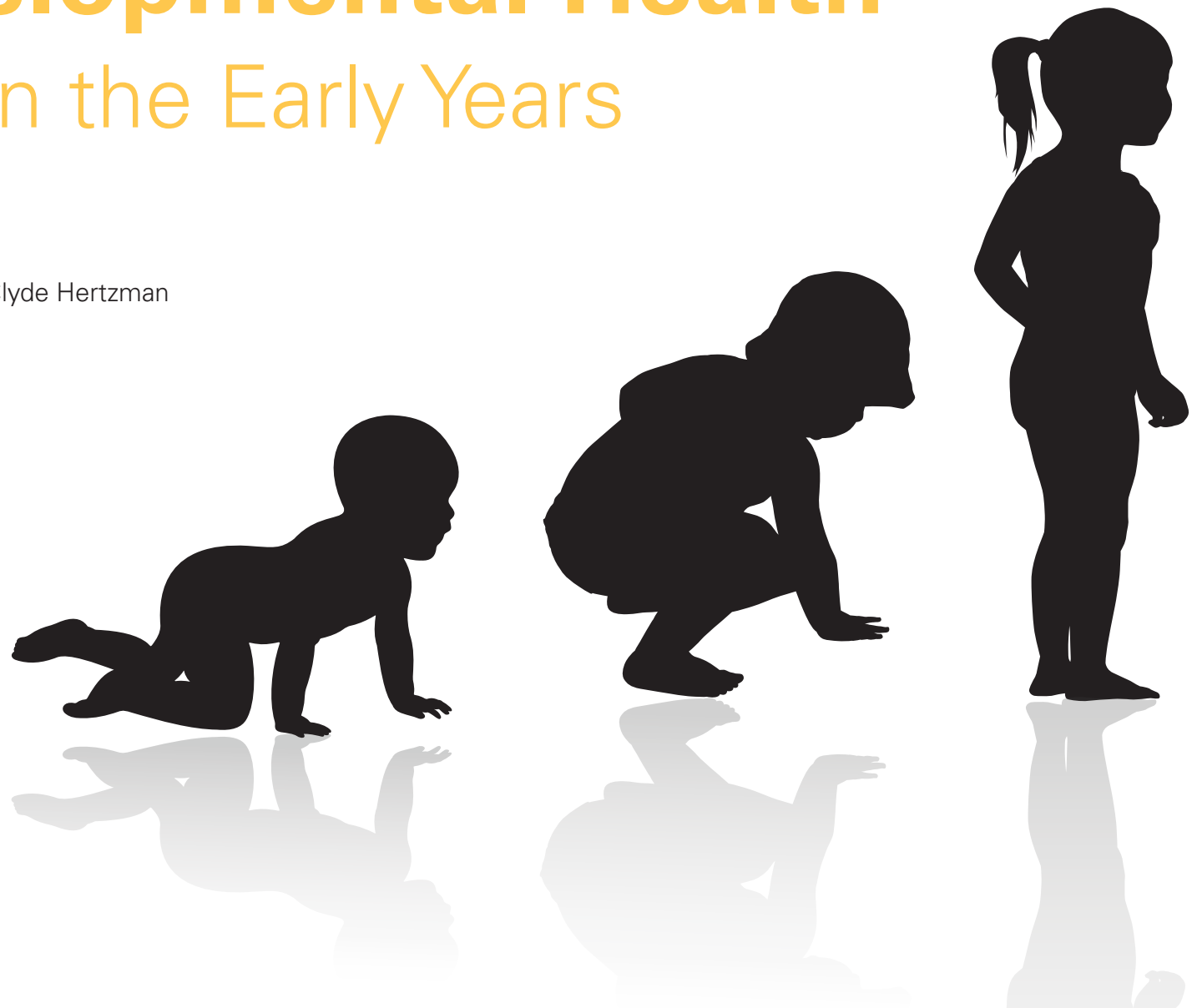

W

hat happens to children in their earliest years is critical for their development throughout the life course. The years from zero to school age are foundational for brain and biological development. Attachment and face recognition; impulse control and regulation of physical aggression; executive function in the prefrontal cortex and focused attention; fine and gross motor functions and coordination; receptive and expressive language; and understandings of quantitative concepts are all established during this time and become embedded in the architecture and function of the brain (Doherty 1997; Kolb 2009; McCain and Mustard 1999). Brain and biological development are in turn expressed through three broad domains of development of the whole child: physical, social-emotional and language-cognitive, which together are the basis of "developmental health" (Keating and Hertzman 1999). Developmental health influences many aspects of well-being, including obesity and stunting, mental health, heart disease, competence in literacy and 


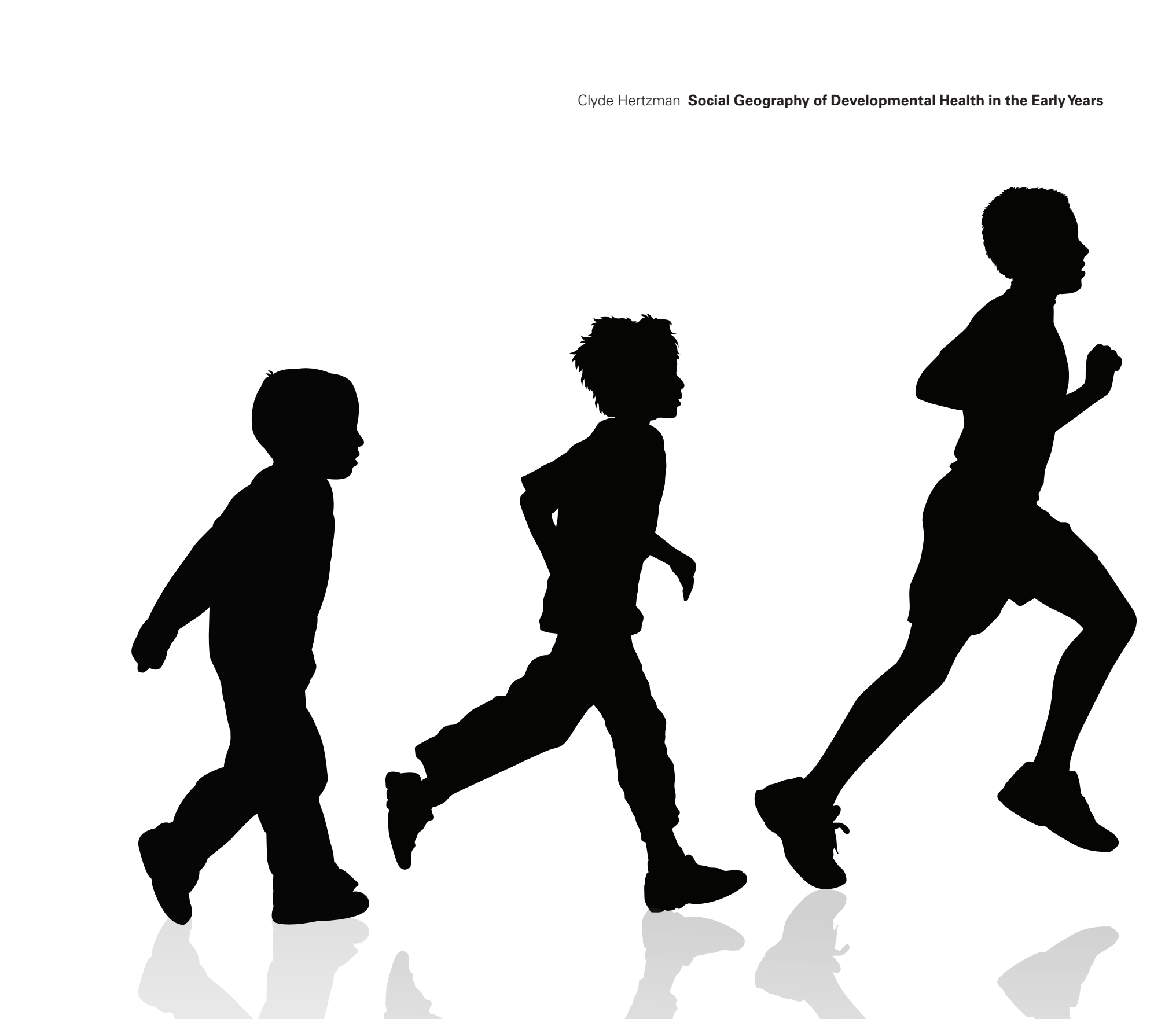


from the poor; rather, any gain in social and economic resources to a given family results in increased prospects for positive development of the children in that family. This stepwise relationship between socio-economic conditions and developmental health is called a "gradient effect" (Keating and Hertzman 1999).

\section{Social Determinants of Developmental Health and Their Geographical Dimension}

Here I present a framework that accounts for the environments (and their characteristics) that directly and indirectly influence the quality of children's early experiences (Figure 1). The framework also acts as a guide to understanding the relationships among these environments, placing the children at the centre of their respective surroundings. The environments are not strictly hierarchical but, rather, are overlapping and interconnected. At the most intimate level is the family environment. At a broader level are residential communities (such as neighbourhoods), relational communities (such as those based on religious or other social bonds) and the early learning, care and development service environment. Each of these environments (where the children actually grow up, live and learn) is situated in a broader socio-economic context that is shaped by factors at the regional, national and global levels. The framework also suggests that historical time is critical. The institutional and structural aspects of societies develop slowly over time and can be very difficult to change. Similarly, those aspects that matter for developmental health are created or dismantled over long periods of time.

The family environment is the primary source of socioeconomic and relational experiences for children, both because family members (or other primary caregivers) provide the largest share of human contact with children and because families mediate children's contact and connection with the broader environment. Young children need to spend their time in warm responsive environments that protect them from inappropriate disapproval and punishment. They need opportunities to explore their world, to play and to learn how to speak and listen to others. Family social resources include parenting skills and education, cultural practices and approaches, intrafamilial relationships and the health status of family members. Economic resources include wealth, occupational status and dwelling conditions. The gradient effect of family resources on developmental health is the most powerful single explanation for inequalities in developmental health across societies, such that societies with steeper gradients have poorer average developmental health (Siddiqi et al. 2007).

Children and their families are also shaped by residential communities (where the children and family live) and
Figure 1. Framework for the social determinants of developmental health

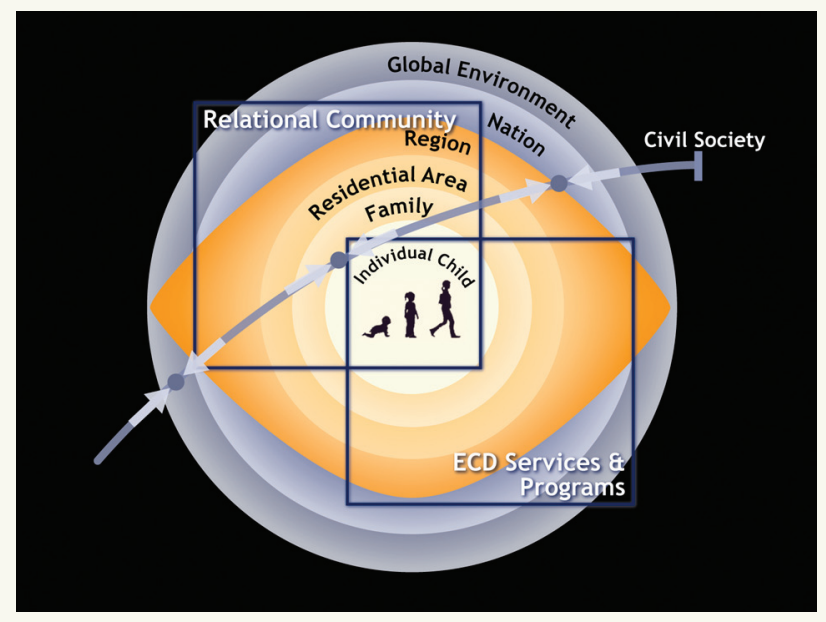

$\mathrm{ECD}=$ early learning, care and development.

relational communities (family social ties to those with a common identity) in which they are embedded. Residential and relational communities offer families multiple forms of support, from tangible goods and services that assist with child rearing to emotional connections with others that are instrumental in the well-being of children and their caregivers. At the residential/locality level, both governments and grassroots organizations play a highly influential role. Many resources available to children and families are provided on a community level through local recognition of deficits in resources, problem solving and ingenuity.

Relational communities are the people, adults and children, who help form children's social identity: tribal, ethnic, religious and language/cultural. Often, they are not geographically clustered communities. Relational communities provide a source of social networks and collective efficacy, including instrumental, informational and emotional forms of support. However, discrimination, social exclusion and other forms of subjugation are often directed at groups defined in relational terms. The consequences of these forms of discrimination (e.g., fewer economic resources) can result in discernable inequalities. Moreover, relational communities can be sources of gender socialization, both equitable and inequitable.

Access to quality early learning, care and development programs and services that support children's development during the early years is crucial for success in childhood. Quality programs provide support for survival, growth and development (Anderson et al. 2003; Clifford et al. 1998; National Institute of Child Health and Human Development Early Child 
Care Research Network 1996; United Nations Educational, Scientific and Cultural Organisation 2007), leading to better child (Burchinal and Cryer 2003; Palfrey et al. 2005) and adult outcomes (Palfrey 2005; Temple and Reynolds 2007), by addressing one or more of the following key issues: breastfeeding, early identification of developmental delays, child care, early childhood education, nutrition, parenting, community strengthening and institutional capacities such as instructional and training programs. In Canada, the list of barriers of access to quality programs includes both geographical and non-geographical factors, for instance, local availability, cost, transportation, time offered, language offered and distrust between parents and service providers.

The influence of the regional and national environments is fundamental in determining the quality and accessibility of services and resources to families and communities. These environments are also salient for understanding the levels of social organization at which inequalities in opportunity and outcome may be manifest, and the levels of organization at which action can be taken to support developmental health.

There are many related aspects of regional environments that are significant for developmental health: physical (e.g., the degree of urbanization, the health status of the population), social, political and economic. These aspects affect developmental health through their influence on family resources, neighbourhood quality and the accessibility and quality of services. In contrast to the statistically powerful impact of family environments on developmental health, the influence of broader environments, such as the region, is statistically weaker but affects much larger numbers of children. Thus, policy changes at a regional level can have a considerable influence on developmental health in the aggregate.

The most salient feature of the national environment is its capacity to affect multiple determinants of developmental health through wealth creation, public spending, child- and family-friendly policies, social protection and the defence of basic rights. At the level of the national environment, comprehensive, intersectoral approaches to policy and decision-making work best. Although developmental health tends to be more favourable in wealthy countries than in poor ones, this is not always the case. The policy-level commitment made by certain resource-poor nations, such as Cuba, has enabled them to create an environment that is far more favourable for developmental health than that in many resource-rich countries.

The global environment can influence developmental health through its effects on the policies of nations as well as through the direct actions of a range of relevant actors, including multilateral economic organizations, industry, multilateral development agencies, non-governmental development agencies and civil society groups. International institutions play both challenging and supporting roles for developmental health. On the challenging side, globalization of the economy has brought the problem of "work life-home life conflict" to many poor countries that do not have the resources to provide quality child care for working parents. This is reflected in the millions of very young children being left home alone, being cared for by other young children or spending their days in their parents' dangerous workplaces in majority world countries (poorer and less developed countries, where the majority of people in the world live; Heymann 2006). On the supportive side, enforcing the United Nations Convention on the Rights of the Child (UNCRC) has the capacity to raise the bar on developmental health in all 193 signatory countries. At present, initiatives are under way to monitor compliance with the Rights in Early Childhood provisions of UNCRC. It is hoped that this will provide a mechanism whereby international scrutiny can be used to increase the priority of investment in early childhood worldwide (Vaghri et al. 2009).

Civil society groups are conceptualized as being organized at, and acting upon, all levels of society. The ability of civil society

\section{Developmental health influences many aspects of well-being, including obesity and stunting, mental health, heart disease, competence in literacy and numeracy, criminality and economic participation throughout life.}
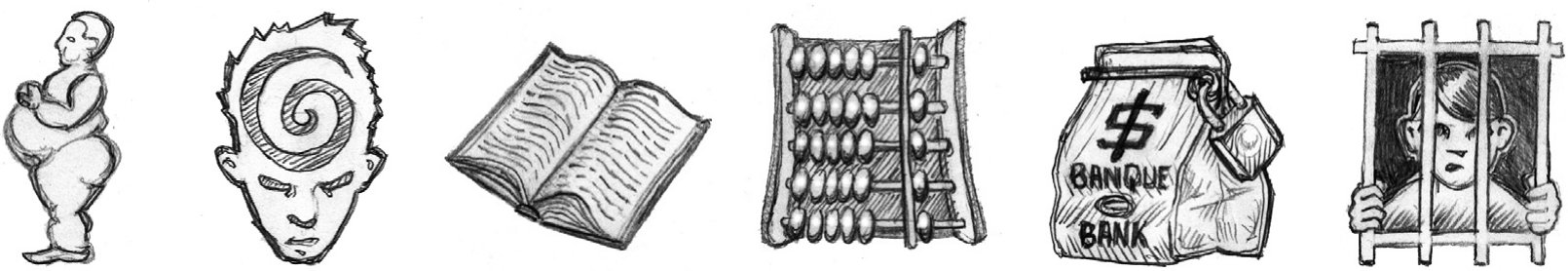
Figure 2. Map of developmental health according to neighbourhood in Greater Vancouver and Greater Victoria

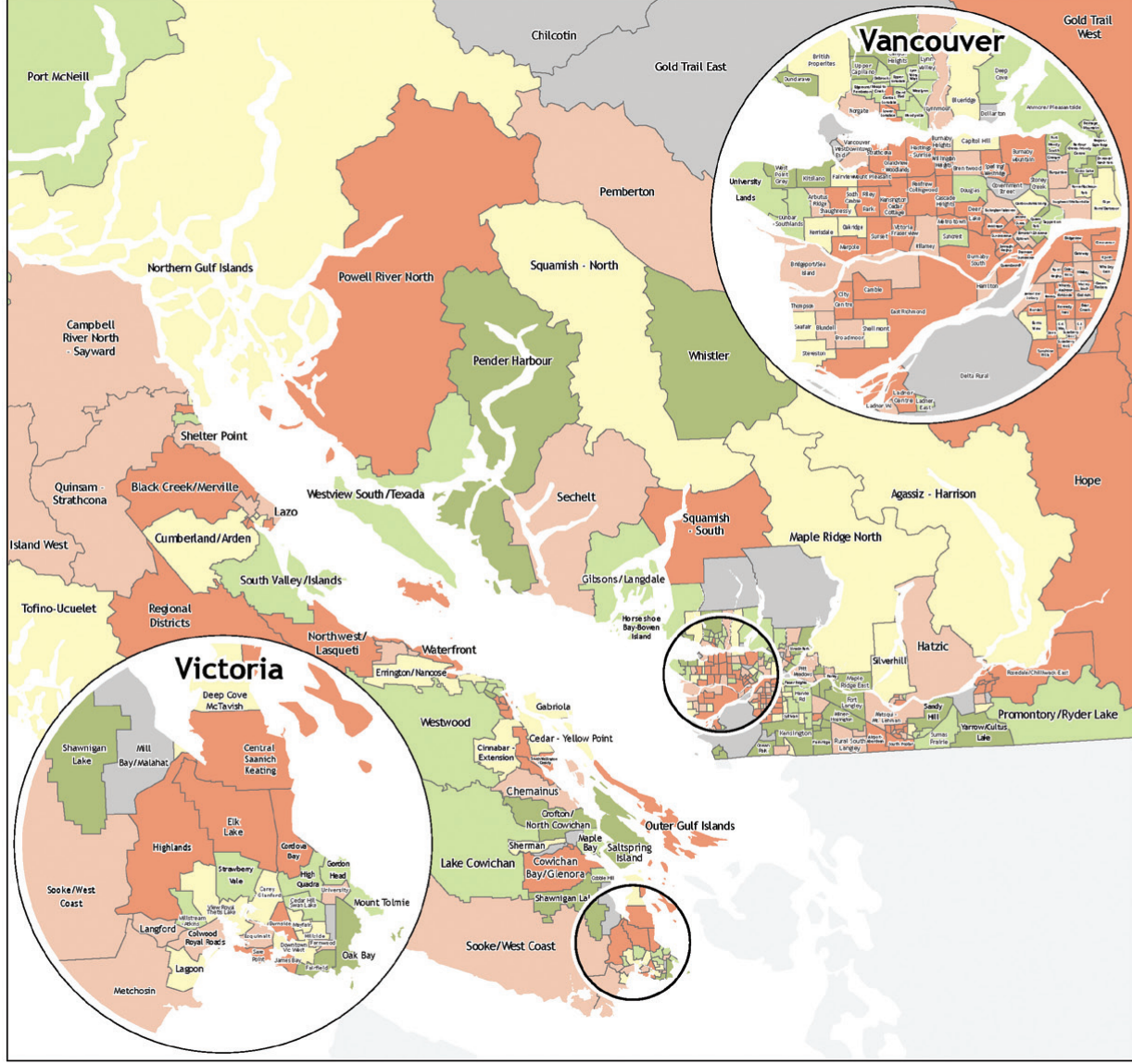

Pan-Canadian EDI

$B C, S K, M B, O N, P E$ \& Montreal

\section{Southwest} British Columbia Vulnerable on One
or More Scales

Percent Vulnerable $4.10-20.00$ $20.01-25.00$ $25.01-29.20$ $29.21-35.63$ $35.64-68.60$ Suppressed Notes: Colour classifcation is
based on the neighbourhood
quintile distribution for the
Pan-Canadian data set.
Source: EDI 2004/05 - 2006/07
ER - HELP - Nov 2009 groups to act on behalf of children is a function of the extent of connectedness of citizens, and the support of political institutions in promoting expressions of civil organization. When civil society is enabled, there are many avenues through which it can engage on behalf of children. These groups can initiate government, non-government and community action on the social determinants of developmental health. They can advocate on behalf of children to ensure that governments and international agencies adopt policies that positively benefit developmental health. Finally, civil society groups are instrumental in organizing strategies at the local level to provide families and children with effective delivery of services; to improve the safety, cohesion and efficacy of residential environments; and to increase the capacity of local and relational communities to better the lives of children.
Institutional/historical time cannot be ignored because the opportunities and barriers that exist for developmental health in every society are the product of evolutionary processes that are measured in years and decades. For instance, the Nordic model of provision in the early years, widely acknowledged to be the best in the wealthy world, unfolded gradually, beginning with policy discussions in the 1950s and evolving over the following 50 years (Bremberg 2009). The fact that all the wealthy Englishspeaking countries invest less (as a proportion of gross domestic product [GDP]) in supporting the positive aspects of early human development than do all the non-English-speaking wealthy countries (Organization for Economic Cooperation and Development [OECD] 2006) is not a result of recent policy decisions but is rooted in the punitive character of the English poor laws of the 17th and 19th centuries, which were exported, 
in spirit and letter, to Canada, the United States, Australia, New Zealand and Ireland (Halfon 2009).

\section{Geography of Developmental Health - Revelations from Mapping}

Between 2000 and 2009, the province of British Columbia completed three population-based assessments of developmental health - including more than $90 \%$ of children in schoolentry cohorts from across the province, at least three times over. Assessments were done during the kindergarten year, and developmental health was measured using the Early Development Instrument (EDI), which involves kindergarten teachers filling out a detailed checklist for each child in their class based on five scale measures of development: physical well-being; social competence; emotional maturity; language and cognitive development; and communication and general knowledge (Janus and Offord 2000). The EDI allows each child to be scored as "vulnerable" or "not vulnerable" on each of these five scales. The label of "vulnerable" is not placed directly on the child. Instead, rates of vulnerability on the EDI are calculated and mapped according to residential neighbourhoods where children live.

Mapping developmental health by neighbourhood follows logically from the framework in Figure 1. Neighbourhoods aggregate family environments, reflect broader environments and also have emergent properties (such as safety and social cohesion) that influence developing children. The Human Early Learning Partnership team at UBC worked with local communities to define neighbourhoods that were coherent as they pertained to young children. In the urban areas, these had to be large enough to include a minimum of 40 kindergarten children per year (range approximately 40-500) but small enough to be recognizable to families and to have a distinct character. Thus, neighbourhoods tended to include families of similar socioeconomic status, unique mixes of relational characteristics and similar levels of access to (or barriers to) programs and services. Over the past year, neighbourhood definitions for EDI have been harmonized across Canada, facilitating pan-Canadian comparisons (Council for Early Child Development 2009).

Figure 2 presents a map of developmental health according to neighbourhood in the most populous area of British Columbia - Greater Vancouver and Greater Victoria - representing a total population of approximately three million and about 30,000 kindergarten children. (The reader is referred to the Council for Early Child Development [2009] to find the full pan-Canadian EDI mapping platform, covering 75-80\% of the Canadian population, and including multiple EDI and socio-economic variables by neighbourhood and region across Canada.) The "proportion of children vulnerable on one or more scales of the EDI" is the summary measure used on this map. The pan-Canadian consortium for the EDI has designated this as its overall summary measure of developmental health, in the same sense that infant mortality is the international summary measure of child survival. What do the maps reveal? The answers are discussed below.

\section{Large Local Area Differences in the Proportion of Developmentally Vulnerable Children}

The colour bands on the map reveal surprisingly large differences in developmental vulnerability across geographical neighbourhoods. Among the green-banded neighbourhoods vulnerability goes as low as $4.1 \%$, and among the red-banded neighbourhoods vulnerability goes as high as $68.6 \%$. The bands were established for the whole the country, so there is more than a 16-fold inequality in developmental vulnerability in Canada at the level of the neighbourhood! This range is much larger than one would have predicted on the basis of random sample surveys of child development, which rarely demonstrate social gradients larger than threefold. Why would this be? The best answer is that local geography defines unique combinations of factors that support or undermine early child development, which are not readily detected by random sample surveys. For analytical purposes, random sample surveys aggregate children from different geographical locales into statistical (rather than real) neighbourhoods according to a small number of grouping factors (e.g., median family income, proportion of adults with high-school graduation). Such "neighbourhood effects" analyses from random sample surveys do not capture the unique circumstances of real neighbourhoods. Thus, the 16 -fold variation in developmental health on the EDI validates the populationbased approach since only this tactic captures the circumstances of real Canadian neighbourhoods.

\section{Across the country as a whole, avoidable vulnerability stands at approximately $60 \%$.}

\section{High Proportion of Avoidable Vulnerability}

Over the past 10 years, the EDI has been performed for several hundred thousand Canadian children, organized into more than a thousand local neighbourhoods. Much like international variations in infant mortality, these data allow us to estimate an achievable minimum level of neighbourhood developmental vulnerability. In principal, the calculation is simple. The lowest level of vulnerability that has been achieved is something that can be achieved. Developmental vulnerability between 4 and $5 \%$ has been accomplished in some (albeit, a very small number of) neighbourhoods in Canada, and this is the range that one would expect based upon clinically significant prematurity, low birth weight and congenital anomalies. Thus, one could assert 
that any level of vulnerability above 5\% is excess and therefore avoidable. Allowing for cohort effects and random variation over time, as we have done in British Columbia, it is responsible to assert, more conservatively, that any vulnerability above $10 \%$ is avoidable. Using this benchmark, in British Columbia, with vulnerability standing at $28.6 \%$ in $2008-2009,65 \%$ can be deemed to be "excess vulnerability." Across the country as a whole, avoidable vulnerability stands at approximately $60 \%$. Moreover, less than 7\% of BC neighbourhoods have demonstrated consistently less than $10 \%$ vulnerability over successive waves of data collection. Thus, vulnerability reduction is an issue for all communities.

\section{Socio-economic Context Doesn't Always Explain Neighbourhood Variation in Developmental Health}

We began with more than 1,000 census and tax filer variables, obtained (through custom orders) from Statistics Canada and Revenue Canada, and matched them to $\mathrm{BC}$ neighbourhoods through aggregation by six-digit postal code. Next, we employed a range of theories as to how socio-economic context might influence developmental health in order to reduce the number of variables and create variable clusters that have theoretical coherence. From these, we constructed models that "explained," in a statistical sense, as much as possible of the variation in vulnerability between neighbourhoods according to socio-economic context. Although the explanatory power varies slightly from wave to wave of EDI data collection, roughly $45-50 \%$ of the neighbourhood variance can be explained in the statistical sense by socio-economic context. This is evidence of the socio-economic gradient effect and demonstrates a steep (i.e., strong) gradient in developmental health in British Columbia. A strong gradient is not unexpected, but it is not easily amenable to modification by the principal agents for young children: families, care providers and social policy makers. On the other hand, more than half of the neighbourhood variation in vulnerability is not explained by socio-economic context. In theory, this ought to be the more easily modifiable variation because it would include such things as day-to-day parenting practices; the quality of local governance and resources for young children; the availability of quality early learning, child care and development programs; and the willingness of families from diverse backgrounds to co-operate in the interests of their children. This leads to the discussion below.

\section{Which Communities Are Positive and Negative Outliers, and Why}

One of the most useful outcomes of population-based data collection and mapping is the capacity to identify positive and negative outliers, that is, neighbourhoods where developmental health is consistently better or worse than one would predict on the basis of socio-economic context across multiple waves of EDI. The population-based character of EDI data collection is indispensable here because it produces neighbourhood vulnerability rates that are not subject to random error, as they would be if children had merely been sampled from neighbourhoods. Thus, positive and negative outliers are exactly that, and not statistical artifacts. When a given neighbourhood is found to be a positive or negative outlier on three successive waves of EDI, one can say with confidence that it has characteristics that are worth exploring. Our research has now reached the stage where we are systematically studying positive and negative outlier neighbourhoods in order to identify their distinguishing characteristics that, we believe, will also be the most readily modifiable community factors that support or undermine developmental health.

\section{FACTS FOR LIFE}

Encouraging children to play and explore helps them learn and develop socially, emotionally, physically and intellectually.

This helps children get ready for school.

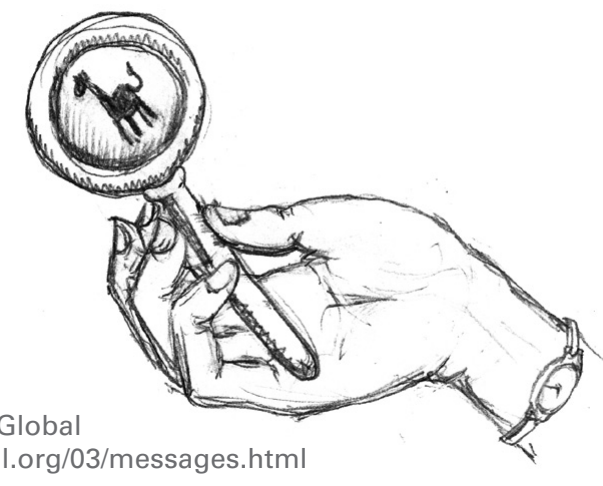

\section{Change in Developmental Health over Time}

With three waves of EDI data collection in British Columbia, it has been possible to analyze trends in developmental health over the first decade of the 21st century. Despite the current high level of interest in the early years, the trends have generally not been favourable. Between wave one (20012004) and wave two (2004-2007) of data collection, overall EDI vulnerability in British Columbia rose from 26.1 to $29.6 \%$. Between wave two and 2008-2009 (when the whole province was done in one school year), vulnerability fell slightly to $28.6 \%$. These trends are reflected at the level of the neighbourhood and geographical school district, where many more places got worse than got better. A closer look, however, shows that the trends vary by scale of the EDI. In particular, vulnerability on 
Table 1. Characteristics of communities showing sustained improvement in developmental health, British Columbia, 2001-2009

Strong intersectoral leadership - Leadership involves a broad coalition of traditional and non-traditional partners where senior leaders attend, significant resources are shared and long-term commitments are honoured.

Focus on EDI outcomes - Community planning focuses on physical, social-emotional and language-cognitive-communication skills, which are given priority over institutional politics.

Multiple layers of programming and support focused on families - Successful communities find ways to make a virtue out of diverse programming by finding ways to coordinate, co-locate and harmonize rules of admission, costs and ages served so that families have choices of programs and fewer scheduling, financial and transportation challenges.

Vertical coordination - Sustainable benefits in developmental health have come when resources have been attracted from governments with taxing authority: local, provincial and national.

Alignment with the school system - The facilities, resources, permanence, credibility and cachet of universal investment in human development that go with the education system are all indispensable to community initiatives in the early years. All communities that have shown sustained improvements in developmental health have pursued a high degree of alignment with the school system, up to and including full integration.

EDI = Early Development Instrument.

the language and cognitive development scale declined, whereas it increased on the physical, social, emotional and communication skills. Since the language and cognitive scale includes most of the traditional "readiness for school" items (e.g., knowing letters and numbers, familiarity with picture books), the trends suggest that we have been placing emphasis on formal learning in the early years, possibly at the expense of other domains of developmental health.

\section{Level of Social Aggregation Where a Problem Exists}

Pan-Canadian mapping of EDI allows variations in developmental health to be readily detected at the level of the community, region, province and nation. This is indispensable for understanding the sources of trends in EDI vulnerability. Once we had determined the overall negative EDI trend in British Columbia, two questions arose. First, was this a BC problem or a Canadian problem? Second, could action at the community level counter the overall trend? Answering these questions requires data to be available at multiple levels of social aggregation. Since British Columbia was not the only province to have collected EDI data over several waves, we were able to determine (from Manitoba and Ontario) that British Columbia was not alone in seeing negative EDI trends between 2000 and 2009. Thus, we focused on national, rather than provincial, explanations for the trend.

With this in mind, we discovered that the mid-1990s were a watershed for Canadian families with children. By then, infant and under-age-five mortality had dropped to the lowest levels in the world (Gapminder 2009). But between 1992 and 1999, social spending in Canada dropped by $19 \%$ as a proportion of GDP (OECD 2004). In 1996, federal-provincial transfer payments were capped, transferring the fiscal crisis of the day from the federal government to the provinces, who provide most of the direct services to families. Starting in 1996, infant mortality began to increase, albeit slightly, for the first time in decades (Public Health Agency of Canada 2008); at the same time, under-age-five mortality stopped decreasing (Gapminder 2009). The year 1996 was also the inflection point for income inequality in Canada and for income inequality among Canadian families with children. Starting then, family income inequality after taxes and transfer payments rose steadily for the following decade (Yalnizyan 2007). At the same time, the number of hours worked by Canadian families with children rose by 300 per year, cutting into quality family time (Yalnizyan 2007). Concurrently, Canada's response to the new realities of working mothers and modern family needs was the weakest in the OECD. In 2008, the United Nations Children's Fund (UNICEF) published its report on benchmarks for early learning and care. Of the 10 benchmarks, Canada achieved only one, tying for last among 26 wealthy countries. In contrast, the Nordic countries all achieved eight to 10 benchmarks. Thus, declining developmental health across Canada was consistent with a broader trend showing that the long-term impact of the solution to the fiscal crisis of the 1990s was damaging to Canadian families with children.

\section{Opportunities for "Place-Based" Learning}

Mapping of developmental health - neighbourhood, regional, provincial, national and over time - allows for many types of learning to take place. It permits large numbers of outlier neighbourhoods and regions to be sampled as if they were individuals and studied in statistically rigorous ways. It allows for the study of factors, such as residential transiency, that do not vary much within regions in Canada but vary significantly over the country as a whole. It makes possible the comparison of the impact of different social policy regimes by province. Finally, it allows hypotheses on the determinants of developmental health to be generated in one part of the country and tested in others. The latter is occurring in relation to the question posed above: could action at the community level counter the overall (negative) trend in developmental health in Canada? Already, ethnographic studies have identified characteristics of $\mathrm{BC}$ communities that have shown sustained improvement in EDI scores over the period 2001-2009 when the national and provincial trends 
were negative (Table 1). These characteristics serve as hypotheses to be tested in other parts of Canada over time.

\section{Conclusion}

Developmental health is socially determined and, in turn, influences health, well-being, learning and behaviour across the life course. Because the social determinants of developmental health and the remedies for developmental vulnerability range from the intimate to the global, population-based data monitoring is indispensable for understanding and intervention. Promulgation of the EDI and community mapping shows promise as tools to help Canada sustain an era of "evidence-based social change" in this field. Such change needs to take place at all levels of society if developmental vulnerability is to be reduced from its current level of more than one quarter of Canadian children to less than one tenth, where we know it should be. $\mathrm{HQ}$

\section{References}

Anderson, L.M., C. Shinn, M.T. Fullilove, S.C. Scrimshaw, J.E. Fielding, J. Normand et al. and the Task Force on Community Preventative Services. 2003. "The Effectiveness of Early Childhood Development Programs." American Journal of Preventive Medicine 24(3 Suppl.): 32-46.

Bremberg S. 2009. "A Perfect 10: Why Sweden Comes Out on Top in Early Child Development Programming." Paediatrics and Child Health 14: 677-80.

Burchinal, M.R. and D. Cryer. 2003. "Diversity, Child Care Quality, and Developmental Outcomes." Early Childhood Research Quarterly 18: 401-26.

Clifford, D., E. Peisner-Feinberg, M. Culkin, C. Howes and S.L. Kagan. 1998. Quality Child Care: Quality Care Does Mean Better Child Outcomes (Spotlight Series No. 2). Chapel Hill, NC: National Center for Early Development and Learning.

Council for Early Child Development. 2009. Pan-Canadian EDI Platform. Vancouver, BC: Author. <http://www.councilecd. $\mathrm{ca} /$ ?q=pancanadianedi_maps $>$.

Doherty, G. 1997. Zero to Six: the Basis for School Readiness (Applied Research Branch Paper No. R-97-3E). Ottawa, ON: Human Resources Development Canada.

Gapminder. 2009. Stockholm, Sweden: Gapminder Foundation. Retrieved October 2009. <http://www.gapminder.org/>.

Halfon, N., S. Russ, F. Oberklaid, J. Bertrand and N. Eisenstadt. 2009. An International Comparison of Early Childhood Initiatives: From Services to Systems. New York: The Commonwealth Foundation.

Heymann, J. 2006. Forgotten Families: Ending the Growing Crisis Confronting Children and Working Parents in the Global Economy. New York: Oxford University Press.

Irwin, L., A. Siddiqi and C. Hertzman. 2007. Early Child Development: A Powerful Equalizer. Geneva, Switzerland: World Health Organization International Commission on the Social Determinants of Health. Retrieved June 29, 2010. <http://www.who.int/social_determinants/ resources/ecd_kn_report_07_2007.pdf>.

Janus, M. and D. Offord. 2000. "Reporting on Readiness to Learn at School in Canada." ISUMA - Canadian Journal of Policy Research 1: 71-75.
Keating, D.P. and C. Hertzman, eds. 1999. Developmental Health and the Wealth of Nations. New York: The Guilford Press.

Kolb, B. 2009. "Brain and Behavioural Plasticity in the Developing Brain: Neuroscience and Public Policy." Paediatrics and Child Health 14: 651-52.

McCain, M. and F. Mustard. 1999. Early Years Study. Toronto, ON: Publications Ontario.

National Institute of Child Health and Human Development Early Child Care Research Network. 1996. "Characteristics of Infant Child Care: Factors Contributing to Positive Care-Giving." Early Childhood Research Quarterly 11: 269-306.

Organization for Economic Cooperation and Development. 2004. Public Social Expenditure by Main Category as a Percentage of GDP (1980-1998). Paris: OECD Publications.

Organization for Economic Cooperation and Development. 2006. Starting Strong II: Early Childhood Education and Care. Paris: OECD Publications.

Palfrey, J.S., P. Hauser-Cram, M.B. Bronson and M.E. Warfield. 2005. "The Brookline Early Education Project: A 25-Year Follow-Up Study of a Family-Centered Early Health and Development Intervention." Pediatrics 116: 144-52.

Public Health Agency of Canada. 2008. The Chief Public Health Officer's Report on the State of Public Health in Canada, 2008. Ottawa, ON: Author.

Shonkoff, J., ed. 2000. From Neurons to Neighborhoods: The Science of Early Childhood Development. Washington, DC: National Academy Press.

Siddiqi, A., I. Kawachi, L. Berkman, S.V. Subramanian and C. Hertzman. 2007. "Variation of Socioeconomic Gradients in Children's Development across Advanced Capitalist Societies: Analysis of 25 OECD Nations." International Journal of Health Services Planning, Administration, Evaluation 37(1): 63-87.

Temple, J.A. and A.J. Reynolds. 2007. "Benefits and Costs of Investments in Preschool Education: Evidence from the Child-Parent Centers and Related Programs." Economics of Education Review $26: 126-44$.

United Nations Children's Fund. 2008. The Child Care Transition (Innocenti Report Card 8). Florence: Innocenti Research Centre.

United Nations Educational, Scientific and Cultural Organisation. 2007. EFA Global Monitoring Report: Strong Foundations, Early Childhood Care and Education. Paris: Author.

Vaghri, Z., A. Arkadas, E. Hertzman and C. Hertzman. 2009. "The Early Childhood Rights Indicators: A Tool to Monitor the Convention on the Rights of the Child and Raise Its Profile Globally." Early Childhood Matters 113: 53-57.

Yalnizyan, A. 2007. The Rich and the Rest of Us. The Changing Face of Canada's Growing Gap. Toronto, ON: Canadian Centre for Policy Alternatives.

\section{About the Author}

Clyde Hertzman, MD, MSC, FRCPC, is the Canada research chair in population health and human development, and director of the Human Early Learning Partnership, University of British Columbia, in Vancouver, British Columbia. 


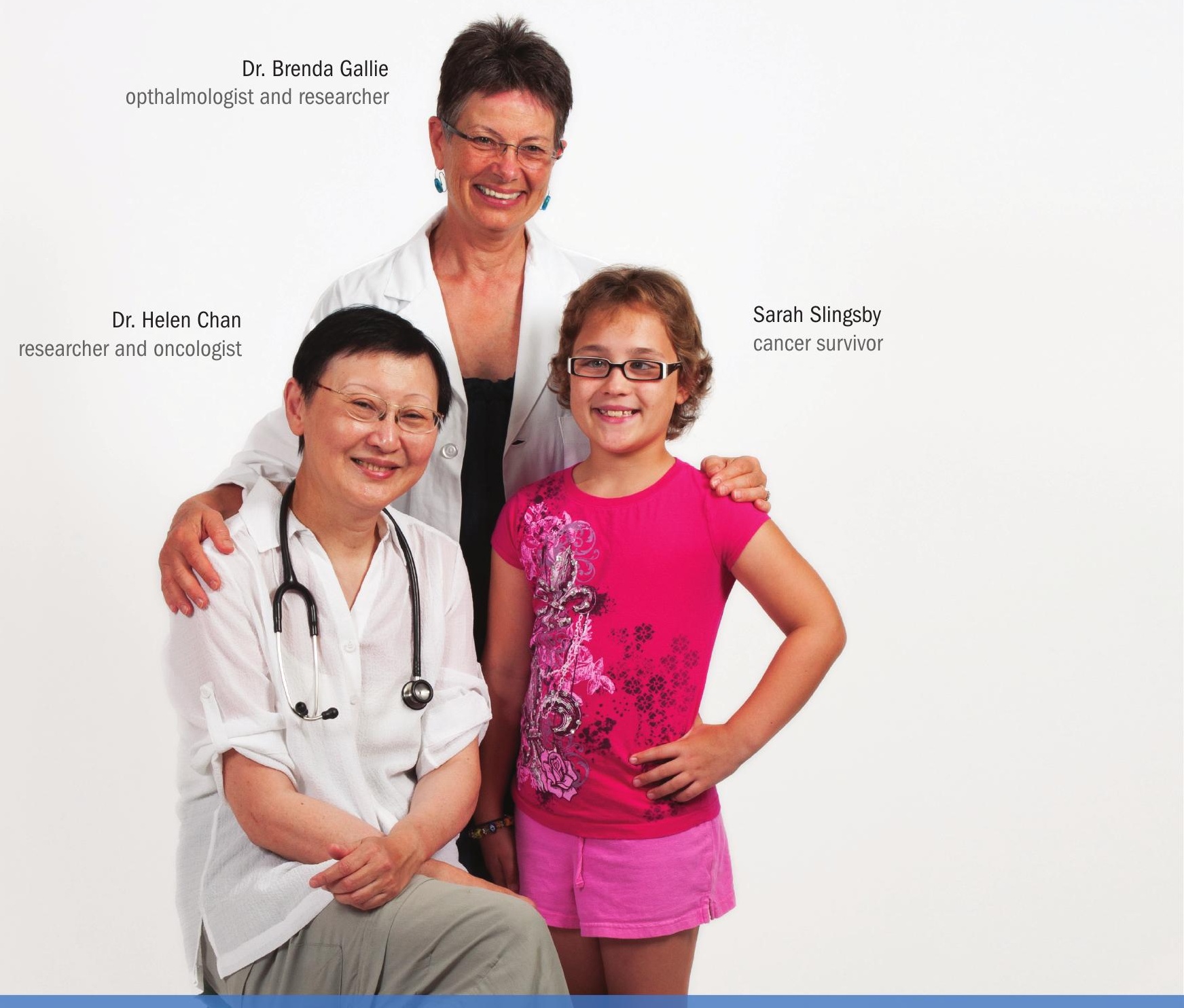

\section{Good science leads to better patient care}

The research and treatment provided by Drs. Helen Chan and Brenda Gallie has helped save the eyesight of untold numbers of children with retinoblastoma, a rare cancer of the eye. Sarah Slingsby is one of them.

Diagnosed last year, the bubbly nine-year-old is now cancer-free.

\section{The Research \& Learning Tower}

